\title{
Ciência, tecnologia e sociedade pelo olhar da Tecnologia Social: um estudo a partir da Teoria Crítica da Tecnologia
}

\author{
Science, technology and society from the perspective of Social Technology: a study from \\ the Critical Theory of Technology
}

Carlos Cesar Garcia Freitas ${ }^{1}$

Andrea Paula Segatto ${ }^{2}$

\section{Resumo}

A tecnologia está inserida de tal forma na vida da sociedade, moldando estilos de vida, que já não é possível tratá-la como um fenômeno isolado da dinâmica social, cerceado por um debate reducionista de cunho técnico científico. Portanto seu planejamento e controle são uma questão política, reivindicada pelo movimento da Ciência, Tecnologia e Sociedade em prol de um envolvimento mais democrático nas decisões que envolvem o contexto científico tecnológico. A finalidade, neste artigo, é discutir a relação entre Ciência, Tecnologia e Sociedade (CTS) e a proposta da Tecnologia Social (TS), utilizando como base teórica a Teoria Crítica da Tecnologia. Para tanto, são apresentados os resultados obtidos com a realização de uma pesquisa descritiva bibliográfica cuja análise é orientada pela descrição dos elementos constituintes da TS e sua implicação à proposta da CTS, no sentido de confirmar sua aderência a esta. Como principais resultados, a TS apresenta grande potencial à CTS e tem em sua proposta crítica os seguintes elementos diferenciais: emancipação do indivíduo, processo de construção social, valorização da aprendizagem, respeito à cultura local, demandas sociais como origem e propósito, apropriação da tecnologia, sustentabilidade, democratização do conhecimento, transformação social e multiplicidade de soluções.

Palavras-chave: Tecnologia Social. Teoria Crítica da Tecnologia. Ciência, tecnologia e sociedade.

\begin{abstract}
Technology is embedded in such a way in society, shaping lifestyles, that it is no longer possible to treat it as an isolated phenomenon of social dynamics, restrained by a reductionist discussion of scientific technical nature. Therefore, planning and controlling it is a political issue, claimed by the movement of the Science, Technology and Society in favor of a more democratic involvement in decisions concerning the scientific technological context. In this sense, the present article aims to discuss the relation between Science, Technology and Society (STS) and the proposal of Social Technology (ST), using as theoretical basis the Critical Theory of Technology. To do so, the results obtained with the realization of a descriptive bibliographic research whose are analysis is guided by describing the components of ST and its implication to the proposal from STS, in order to confirm its adherence to the last one. As main results, ST has great potential to aggregate to STS and in its critical proposal, there are the following advantages: emancipation of the
\end{abstract}

Artigo submetido em 26 de fevereiro de 2013 e aceito para publicação em 13 de dezembro de 2013.

DOI: http://dx.doi.org/10.1590/1679-39517420

1 Professor adjunto da Universidade Estadual do Centro Oeste; Doutor em Administração pela Universidade Federal do Paraná. Endereço: PR 153, Km 7, CEP 84500-000, Irati - PR, Brasil. E-mail: cesarfreitas@sercomtel.com.br

2 Professora adjunta da Universidade Federal do Paraná; Doutora em Administração pela Universidade de São Paulo. Endereço: Av. Prefeito Lothario Meissner, 632 - 2o andar - Jardim Botânico, CEP 80210-170, Curitiba - PR, Brasil. E-mail: aps@ufpr.br 
individual, social construction process, appreciation of learning, respect for local culture, social demands as origin and purpose, ownership of technology, sustainability, democratization of knowledge, social change and multiplicity of solutions.

Keywords: Social Technology. Critical Theory of Technology. Science, technology and society.

\section{Introdução}

A força da acumulação do capital, baseada nos modelos de produção e consumo dominantes, intensificada pela globalização, tem conduzido à crença da privatização do público e de que as forças relevantes são apenas os mercados globais e as empresas transnacionais (SACHS, 1997; BOCAYUVA, 2009). Porém, de forma recorrente e incisiva, a intervenção dos estados por meio de políticas visando ao desenvolvimento é destacada, pelo Programa das Nações Unidas para o Desenvolvimento, como caminho essencial para a mudança.

Observa-se que "[...] a capacidade tecnológica para transformar a natureza e a orientação do desenvolvimento é tal que quem controla a tecnologia controla o desenvolvimento" (HAMMARSKJÖLD, 1975, p. 29, tradução nossa). Desse modo, entre os muitos caminhos a serem tomados para mudar a situação, um é essencial: a tecnologia.

Apesar de sua essencialidade, diversas são as alternativas tecnológicas que se apresentam requerendo uma escolha criteriosa. Cabe destacar que a humanidade possui conhecimento, tecnologia, engenhosidade e recursos jamais registrados anteriormente em nossa história, porém, para que possam ser justamente aproveitados por todos, faz-se necessária a instauração de novos conceitos e novos valores para mobilizar a vontade (WCED, 1987). O que implica repensar nosso modelo de desenvolvimento tecnológico, assumindo o compromisso ético de resgatar os valores de igualdade, equidade e solidariedade nas questões econômicas (SACHS, 2008).

No presente artigo visa-se discutir a relação: Ciência, Tecnologia e Sociedade (CTS) e a proposta da Tecnologia Social (TS) da ótica da Teoria Crítica da Tecnologia.

\section{Procedimentos Metodológicos}

Nesta seção são apresentados os procedimentos utilizados na realização da pesquisa que deram origem ao conteúdo deste artigo. Para tanto, são delineados mediante as seguintes classificações: objetivo, tipo de pesquisa e estratégia.

Quanto ao objetivo, buscou-se por meio da pesquisa, evidenciar diversos aspectos que denotam o potencial da proposta da Tecnologia Social em responder as demandas por uma adequada relação entre a ciência, a tecnologia e a sociedade.

O tipo da pesquisa caracteriza-se como descritivo, uma vez que a finalidade foi descrever elementos fundamentais dos fenômenos: Ciência, Tecnologia e Sociedade (CTS) e Tecnologia Social (TS); bem como analisar as relações existentes entre estes, conforme destacam Richardson (1999) e Trivinõs (2010) a respeito da aplicação da pesquisa descritiva.

Como estratégia foi empregada a análise bibliográfica, uma vez que as fontes de dados utilizadas constituíram-se de literatura de referências, como livros e artigos científicos (MARCONI e LAKATOS, 2003). O emprego dessa estratégia é justificado pelo fato de a especificidade do estudo centrar-se no conjunto de conhecimentos registrados, de modo especial, por dois autores: Feenberg (1991), criador da Teoria Crítica da Tecnologia, empregada como viés teórico das análises; e Dagnino (2004), que, além de ser 
o principal pesquisador e escritor sobre o fenômeno TS, também conduziu a elaboração do arcabouço teórico da TS.

Vale salientar que a pesquisa foi financiada com recursos da Fundação Araucária, órgão de fomento ligado à Secretaria da Ciência, Tecnologia e Ensino Superior do Paraná, mediante Programa Universal de pesquisa básica e aplicada, convênio 172/2012 com a Universidade Estadual do Centro Oeste (UNICENTRO).

Após essa breve introdução, apresenta-se a seguir o referencial teórico, destacando-se os principais conceitos envolvidos no estudo. Cabe salientar que a presente proposta teórica está centrada em três arcabouços, que constituem as subsessões do referencial: ciência, tecnologia e sociedade; teoria crítica da tecnologia; e tecnologia social.

\section{Referencial Teórico}

\section{Ciência, Tecnologia e Sociedade}

Ciência, Tecnologia e Sociedade (CTS) representa o estudo das relações existentes entre a ciência, a tecnologia e a sociedade, e forma um campo de trabalho voltado tanto para a investigação acadêmica como para as políticas públicas. Fundamenta-se em novas correntes de investigação em filosofia e sociologia com foco no entendimento da triangulação entre a ciência, a tecnologia e a sociedade (BAZZO, LINSINGEN e PEREIRA, 2000).

Tem como motivação básica a busca pela compreensão do processo histórico-social do desenvolvimento tecnológico (TRIGUEIRO, 2009), e coloca-se em uma posição de reivindicação da sociedade para um envolvimento mais democrático nas decisões que envolvem o contexto científico tecnológico ao qual pertence.

A intensificação dos debates acerca da CTS decorre da percepção de que a tecnologia passou a ser um elemento tão importante ao desenvolvimento que este já não pode ser concebido sem ela, e "[...] qualquer país que falhe na utilização eficaz da tecnologia acaba, provavelmente, por se atrasar no desenvolvimento humano e ficar marginalizado na economia mundial" (PNUD, 2001, p. 1). O país, por mais pobre que seja, não pode omitir-se em suas decisões políticas a respeito da tecnologia, nem mesmo deixar essa tarefa a terceiros, aceitando modelos preestabelecidos.

O que se constata é que "[...] a capacidade tecnológica para transformar a natureza e a orientação do desenvolvimento é tal que quem controla a tecnologia controla o desenvolvimento, o que torna tal questão essencialmente política" (HAMMARSKJÖLD, 1975, p. 17, tradução nossa). É preciso trazer ao controle do Estado as decisões sobre que tipo de desenvolvimento se deseja e colocar em prática ações que levem a um desenvolvimento que seja sustentável. Para isso, é preciso compreender que o papel da ciência e tecnologia (C\&T), diferentemente de exercer uma orientação técnica e científica, deve ser baseado em uma decisão política, por meio de uma visão crítica sobre a forma adequada de se conceber a relação entre homem e natureza. No enfrentamento deste dilema, tal posição tem consequências importantes na forma de conceber o papel da ciência e, na verdade, da expertise em geral (ROBINSON, 2004).

Condição que implica mudar o paradigma dominante baseado no modelo linear da ciência e tecnologia, uma vez que "[...] a crença de que os progressos científicos são convertidos em utilizações práticas por meio de um fluxo dinâmico que vai da ciência à tecnologia tem sido em toda parte um lugar-comum entre os administradores de pesquisa e desenvolvimento" (STOKES, 2005, p. 27-28).

O modelo linear da C\&T moldou a visão predominante do relacionamento entre ciência e tecnologia; sua consequência foi a criação de "[...] um paradigma geral para a interpretação da natureza da pesquisa, que ainda hoje se encontra notavelmente difundido entre as comunidades científicas e de políticas, e também no 
entendimento popular" (STOKES, 2005, p. 28-29). O resultado desta condição é que o desenvolvimento tecnológico estaria fora do controle político, ou seja, na orientação ou escolha da tecnologia não se consideram os interesses sociais, mas apenas os fatores técnicos econômicos justificados pelas eficiências da tecnologia.

Acerca disso, Dagnino (2007) apresenta dois focos distintos de orientação do desenvolvimento da C\&T e sua implicação para a sociedade. No primeiro, o foco privilegiado é a própria $C \& T$ e "[...] se caracteriza pela suposição de que a C\&T [...] avança contínua e inexoravelmente, seguindo um caminho próprio, podendo ou não influenciar a sociedade de alguma maneira" (DAGNINO, 2007, p. 3). Nesse caso, a tecnologia por si só é desvinculada de seu contexto, ou seja, é um elemento neutro e a diferença básica entre as tecnologias estaria em ser mais ou menos avançada (eficiência técnica).

O foco na C\&T caracteriza o paradigma do modelo linear e acaba se desdobrando em duas abordagens ou variantes. A primeira, a abordagem da neutralidade, posiciona a C\&T como não "[...] influenciada pelo contexto social e sem poder de determinar a sua evolução, sendo então desprovida de valor e dele independente" (DAGNINO, 2007, p. 19). A segunda, a abordagem do determinismo, entenderia o desenvolvimento da C\&T como "[...] uma variável independente e universal que determinaria o comportamento de todas as outras variáveis do sistema produtivo e social; como se ela dependesse inteiramente das mudanças e da organização tecnológica" (DAGNINO, 2007, p. 19).

O segundo foco, a sociedade, é o elemento privilegiado. Reside na crença de que o desenvolvimento da C\&T não é endógeno ou autônomo, mas, sim, influenciado pelo contexto social, e se desdobra também em duas abordagens ou variantes.

A primeira abordagem, denominada tese fraca da não neutralidade, “[...] postula que o contexto engendrado pelas relações sociais e econômicas e pelos imperativos de natureza política conforma o ambiente em que é gerado o conhecimento científico e tecnológico" (DAGNINO, 2007, p. 54). Desse modo, o conhecimento científico e tecnológico incorpora ou internaliza valores, condições ou características de seu ambiente.

A segunda abordagem, denominada tese forte da não neutralidade, concorda com a visão da tese fraca, porém aprofunda as implicações da tecnologia sobre o contexto em que é utilizada. "A C\&T gerada sob a égide de determinada sociedade e, portanto, construída de modo a ela funcional está de tal maneira 'comprometida' com a manutenção desta sociedade que não é passível de ser utilizada por outra sociedade" (DAGNINO, 2007, p. 54-55).

Isto se deve ao fato de que a tecnologia, quando utilizada em um contexto diferente ao de sua origem, tende a reproduzir as relações sociais prevalecentes, que estão internalizadas em sua concepção. Desse modo, tornase inadequada para um contexto diferente daquele para a qual foi criada, provocando uma série de disfunções e desequilíbrios ao novo contexto.

Ainda, em uma análise crítica sobre a tecnologia, aprofundando os estudos sobre o modo que se tem abordado a relação entre C\&T e sociedade, Dagnino (2007) e Dagnino, Brandão e Novaes (2004) empreenderam esforços na busca por compreender as diversas visões possíveis para o modo como a C\&T pode ser empregada. Como resultado descreveram quatro visões possíveis: determinismo, instrumentalismo, substantivismo e teoria crítica (Quadro 1). 


\section{Quadro 1}

\section{Visões sobre a Tecnologia}

\begin{tabular}{|c|c|c|c|}
\hline & & & \\
\hline & DETERMINISMO & INSTRUMENTALISMO & \\
\hline & $\begin{array}{l}\text { teoria da modernização; visão } \\
\text { marxista tradicional; força motriz } \\
\text { da história; conhecimento do } \\
\text { mundo natural serve ao Homem } \\
\text { para esse adaptar-se à natureza }\end{array}$ & $\begin{array}{l}\text { fé liberal no progresso; visão } \\
\text { moderna padrão; ferramenta por } \\
\text { meio da qual satisfazemos } \\
\text { nossas necessidades }\end{array}$ & \\
\hline AUTÔNOMA & $\leftarrow$ & & $\begin{array}{c}\text { CONTROLADA PELO } \\
\text { HOMEM }\end{array}$ \\
\hline & SUBSTANTIVISMO & TEORIA CRÍTICA & \\
\hline & $\begin{array}{l}\text { meios e fins determinados pelo } \\
\text { sistema; não é meramente } \\
\text { instrumental, incorpora um valor } \\
\text { substantivo, e não pode ser } \\
\text { usada para propósitos } \\
\text { diferentes, de indivíduos ou } \\
\text { sociedade }\end{array}$ & $\begin{array}{l}\text { opção por meio-fins alternativos; } \\
\text { reconhece o substantivis mo, } \\
\text { mas vê graus de liberdade; o } \\
\text { desafio é criar instituições } \\
\text { apropriadas de controle }\end{array}$ & \\
\hline & $\begin{array}{l}\text { CON } \\
\text { POR }\end{array}$ & $\begin{array}{l}\text { NADA } \\
\text { DRES }\end{array}$ & \\
\hline
\end{tabular}

Fonte: Dagnino, Brandão e Novaes (2004, p. 48).

Essas visões estão norteadas por dois aspectos principais: neutralidade e autonomia. Desse modo, cada visão compreende uma perspectiva entre a neutralidade (condicionada por valores) e a ausência desta, e autonomia (controlada pelo homem) e não autonomia.

O eixo vertical corresponde a um continuum entre os extremos da neutralidade - no qual a tecnologia é neutra por natureza, ou seja, concebida de modo imparcial, livre de interesses, sejam estes econômicos, políticos, morais ou sociais, inseridos em seu contexto social - e da não neutralidade, ou condicionada por valores. Neste extremo, a tecnologia é carregada de valores e sua utilização acaba por reforçá-los (DAGNINO, 2007). "Segundo a perspectiva neutra, o resultado material da tecnologia, um dispositivo técnico qualquer, é simplesmente uma concatenação de mecanismos causais que pode ser usada para o bem ou para o mal" (DAGNINO, 2007, p. 172-173).

Já o eixo horizontal corresponde ao continuum entre os extremos da autonomia e do controle humano. Do extremo da autonomia dá-se a crença de que "[...] a tecnologia, apoiada na ciência e no método científico, e em busca da eficiência crescente, teria suas próprias leis imanentes, seguindo uma trajetória linear e inexorável, governada por esse impulso endógeno" (DAGNINO, 2007, p. 173).

Nesta situação, a tecnologia segue livremente seu caminho, orientada pelo seu desenvolvimento em si, neutra e livre de qualquer intervenção social; cabe à sociedade apenas tirar o melhor proveito de seus benefícios. No extremo oposto está a posição controlada pelo homem, condição na qual os homens têm total controle sobre a tecnologia, decidindo sua orientação e seu desenvolvimento.

No primeiro quadrante tem-se a visão determinista da tecnologia, que combina as perspectivas de autonomia e neutralidade. Nesse caso, a tecnologia independe da vontade humana e de seus valores, sendo um fim em si mesma; a sociedade é refém da tecnologia, as exigências de eficiência e progresso são moldadas por essa mediante (DAGNINO, BRANDÃO e NOVAES, 2004). A visão determinista caracteriza o foco na C\&T pela abordagem do determinismo tecnológico, que tem na tecnologia as razões do 
desenvolvimento econômico, justificado pela busca da racionalidade refletida na eficiência técnica e corresponde ao modelo linear da C\&T.

No segundo quadrante tem-se a visão instrumental da tecnologia, que combina as perspectivas de neutralidade e de controle pelo homem. Neste caso, a tecnologia, em sua concepção, é pura, isenta de valores ou interesses, porém está subordinada ao arbítrio humano. "É uma visão moderna padrão, que concebe a tecnologia como um instrumento da espécie humana mediante a qual satisfazemos nossas necessidades, determinando a direção do desenvolvimento tecnológico de acordo com nossa vontade" (DAGNINO, BRANDÃO e NOVAES, 2004, p. 48).

Apesar de a visão instrumental romper com os pressupostos do determinismo, que preconiza o avanço independente do desenvolvimento tecnológico, não elimina o foco restrito à $C \& T$ em detrimento da sociedade, mantendo válido o modelo linear, pois as justificativas das escolhas tecnológicas ainda recaem sobre a racionalidade técnica.

Desse modo, dada sua isenção de valores, a tecnologia pode ser utilizada de modo indistinto de qualquer perspectiva de valor. Isto quer dizer que a tecnologia adotada está desvinculada dos valores sociais de sua origem. "Para a visão instrumental, o objeto tecnológico é em si neutro, o que faz a diferença é o emprego que dele se faz" (NOVAES e DAGNINO, 2004, p. 5).

No instrumentalismo, a tecnologia, assim como o avanço tecnológico, dependem das escolhas da sociedade; geralmente feitas de modo aleatório, uma vez que se trata de um mero recurso que pode ser utilizado de forma indistinta onde quer que seja aplicado.

No terceiro quadrante tem-se a visão substantivista da tecnologia, que combina as perspectivas de autonomia e condicionada por valores. Consiste em um avanço que rompe com o foco na C\&T para a sociedade e traz em si o questionamento a respeito do desenvolvimento da tecnologia. Sua abordagem reside na tese fraca da não neutralidade da $C \& T$, pois compreende que as características do desenvolvimento tecnológico são determinadas pela sociedade de origem.

$\mathrm{O}$ aspecto do condicionamento de valores deve-se ao fato de que a eficiência que justifica a criação da tecnologia está vinculada a um conjunto de valores de sua origem. Desse modo, a tecnologia não é abstrata, mas, sim, substantiva; está a serviço do modo ideal ou de bem viver da existência humana (DAGNINO, 2007).

A consequência da autonomia e do condicionamento de valores está no fato de que, uma vez criada, a tecnologia pode ser reaplicada em um lugar diferente, porém, com os mesmos valores do local de origem. Caso contrário, esta tecnologia inviabilizaria os propósitos destes indivíduos ou sociedades. O que explica em muito a ineficiência da transferência de tecnologia entre sociedades que cultivam valores diferenciados.

No quarto quadrante, tem-se a visão da teoria crítica, que combina as perspectivas controle pelo homem e condicionada por valores e é decorrente da Teoria Crítica da Tecnologia, de Feenberg (2004). Caracteriza-se pela não neutralidade, pois é dotada dos valores inerentes à sua concepção e é controlada pelo homem, subordinada aos seus interesses (DAGNINO, 2007).

A visão da teoria crítica corresponde ao foco na sociedade, mediante o qual o desenvolvimento da C\&T não é endógeno, mas influenciado pela sociedade, e carrega em si a abordagem da tese forte da não neutralidade. Diferente da visão substantiva, a visão da teoria crítica é otimista em relação à tecnologia e sua capacidade de promover um desenvolvimento que atenda às necessidades da sociedade e reforce os valores que esta escolheu para viver. Nesse caso, é preciso que haja o controle social que oriente o desenvolvimento da C\&T em uma perspectiva diferente da orientação técnica, posicionando as necessidades das pessoas em primeiro lugar (ROBINSON, 2004), ou seja, trocando-se a racionalidade técnica pela racionalidade democrática, segundo a qual toda tecnologia está a serviço da humanidade e, não, o inverso. 


\section{Teoria Crítica da Tecnologia}

A Teoria Crítica da Tecnologia, criada por Feenberg (2004), defende a tese de que "[...] onde quer que as relações sociais sejam mediadas pela tecnologia moderna, é possível introduzir controles mais democráticos e reformular a tecnologia a fim de acolher maiores inputs de perícia e iniciativa" (FEENBERG, 2004, p. 2$3)$.

O autor considera não ontológica sua crítica da tecnologia, porém, mantém a força da crítica ontológica de Herbert Marcuse, com quem estudou; "[...] trata-se de um enfoque que prolonga as análises da Escola de Frankfurt, aspirando a reconstruir a ideia de socialismo com base numa radical filosofia da tecnologia" (CUPANI, 2004, p. 508), e nos ensinamentos de pensadores como Marx, e neomarxistas como Marcuse, Habermas, Hawls, Adorno, entre outros.

Por meio de um processo dialético "[...] a tecnologia media e molda os grupos sociais que, por sua vez, mediam e moldam a tecnologia" (FEENBERG, 2009, p. 115). Desse modo, "[...] segundo a teoria crítica, a tecnologia existente 'emolduraria' não apenas um estilo de vida, mas muitos possíveis estilos diferentes, cada um refletindo diferentes escolhas de design e diferentes extensões da mediação tecnológica" (DAGNINO, 2004, p. 50).

A implicação direta disso é que as tecnologias não seriam meros artefatos ou ferramentas, dispostos aleatoriamente a serviço do homem, em uma relação reducionista, mas, ao contrário, serviriam como suportes a estilos de vida.

Considerando a capacidade embutida na tecnologia de influenciar o modo de vida, desvela-se a não neutralidade da técnica, e faz-se necessário o resgate da discussão do desenvolvimento tecnológico do campo técnico e científico para o campo político, principalmente considerando que a C\&T tradicionalmente tem se orientado pelo mercado.

O modo como é concebida hoje, por meio de uma lógica global baseada na racionalidade instrumental, influenciada pela ordem dominante capitalista, deixa claro que a tecnologia não é apenas "[...] um mero instrumento neutro, pois encarna valores antidemocráticos provenientes da sua vinculação com o capitalismo e manifestos numa cultura de empresários, que enxerga o mundo em termos de controle, eficiência e recursos" (CUPANI, 2004, p. 508).

No paradigma atual, a escolha da tecnologia é justificada pela eficiência técnica, com base na racionalidade instrumental, como indicador de sucesso, porém Feenberg (2005) defende que o critério técnico de eficiência não é decisivo no processo, pois escolhas sociais o influenciam. Escolhas norteadas por valores distintos recaem sobre várias opções, muitas viáveis e que competem entre si. Dessa forma, tecnologias que preservam os valores dominantes seriam privilegiadas.

Dessa maneira, o processo de escolha, que ingenuamente pode ser considerado neutro, é completamente enviesado pelo código técnico definido em algum momento pelos interesses sociais dominantes. O código técnico consiste, então, em um critério de escolha aplicado a diversos projetos e tem como fundo a realização de um interesse particular.

A influência do código técnico nas escolhas reflete as "[...] instrumentalizações secundárias da teoria da instrumentalização, tais como mediações éticas e estéticas reforçadas por indivíduos que agem em seu próprio interesse e pelo interesse da lei" (FEENBERG, 2005, p. 4), influenciando a racionalidade do processo. Ou seja, a escolha, em lugar de ser uma decisão racional, acaba por ser uma posição socialmente relativa. O processo de influência da escolha tecnológica pela tendência tecnocrática pode ser esquematizado conforme a Figura 1. 
Figura 1

\section{Processo de influência da escolha tecnológica}

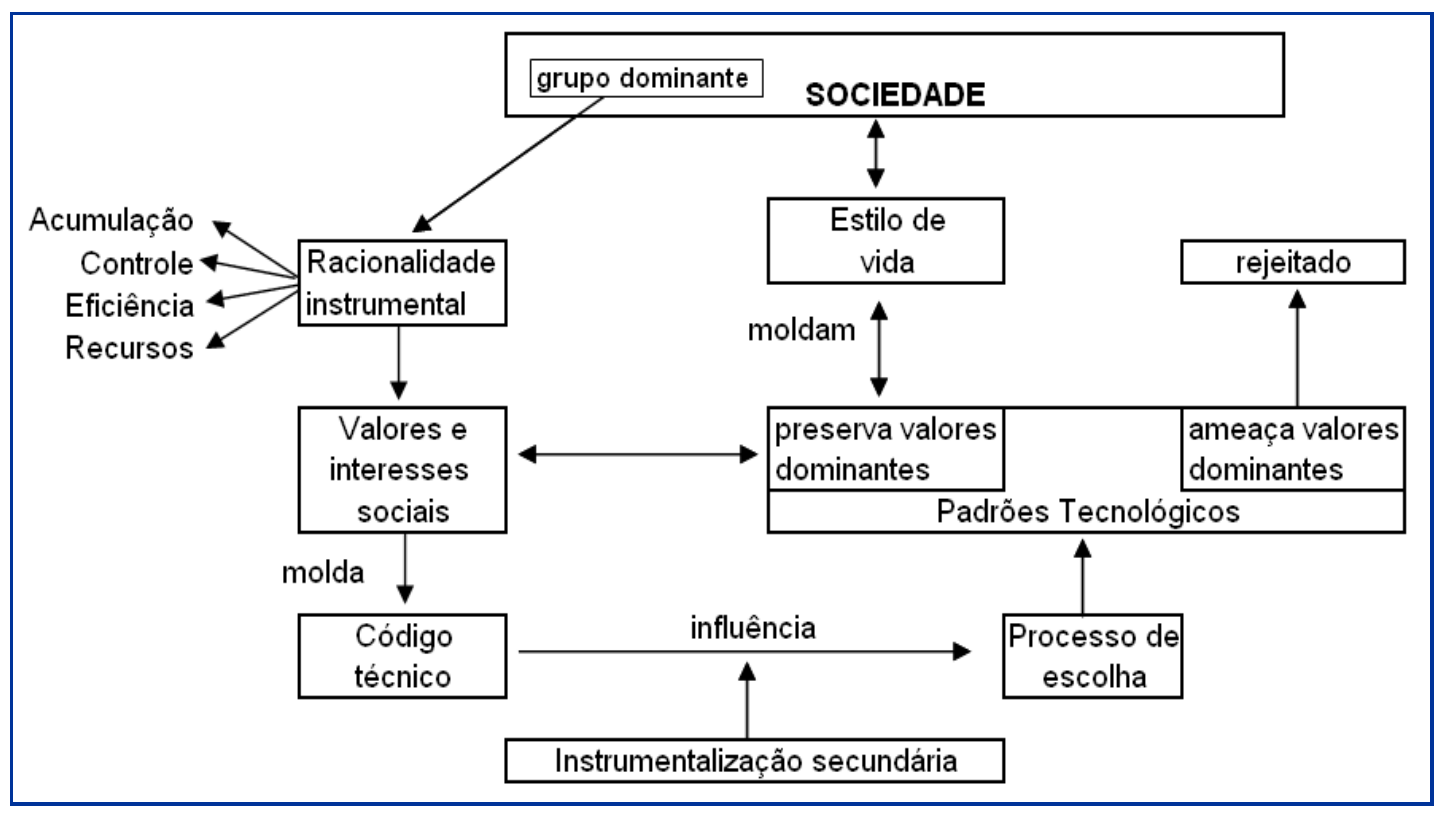

Fonte: Desenvolvido pelos autores com base em Feenberg (2004), Feenberg (2005) e Feenberg (2009).

Devido ao processo de instrumentalização, a tecnologia é vista como algo justificado e neutro de qualquer interesse. Isto é, acredita-se que a tecnologia que se apresenta foi escolhida por ser a melhor opção em termos de eficiência técnica e não por ter sido estabelecida por algum grupo social de maior poder.

Outro aspecto que reforça a crença da neutralidade está no que Feenberg $(2005$, p. 1) chama de ilusão da transcendência, que diz respeito ao lapso de tempo entre a utilização da tecnologia e a percepção de seus malefícios, decorrentes da ação técnica. Isto se deve ao fato de que "[...] o assunto técnica não escapa da lógica da finitude [...] mas a reciprocidade da ação finita é dissipada ou adiada de tal maneira e de tal forma que crie o espaço de uma necessária ilusão de transcendência".

Cria-se a falsa impressão de que o reflexo ou o resultado da tecnologia de que se faz uso no momento presente não afeta o futuro. Essa característica da tecnologia deve-se à ação técnica da relação entre o humano e a técnica. "Chamamos de uma 'ação técnica' quando o impacto sobre o objeto está fora de toda proporção ao feedback de retorno que afeta o agente", explica Feenberg (2004, p. 5). Isso explica em muito a facilidade com que a sociedade aceita as novidades tecnológicas de modo tão acrítico.

A tecnologia pode ser e é configurada de tal forma que reproduz a regra de poucos sobre muitos [...] A sociedade é organizada ao redor da tecnologia, o poder tecnológico é a fonte de poder desta sociedade. Isto fica claro nos designs de equipamentos tecnológicos que estreitam a escala dos interesses e preocupações que podem ser representados pelo funcionamento normal da tecnologia e das instituições que dependem dela. (FEENBERG, 2005, p. 2).

Da não compreensão dos interesses ou preocupações herdadas da tecnologia adotada, dá-se o que Feenberg (2009, p. 102) denomina de paradoxo do óbvio, ou seja, “[...] o que é mais óbvio está mais oculto; objetos diferem das coisas e pessoas comuns na maneira como eles se relacionam ao tempo; as tecnologias parecem desligar-se do seu passado". 
Assim, a ilusão da transcendência, a ação técnica e o paradoxo do óbvio são elementos que obscurecem a compreensão sobre os interesses por trás das escolhas tecnológicas, ou mesmo do processo que orienta a C\&T. O resultado disso é que as tecnologias são aceitas acriticamente como instrumentos autojustificados e inofensivos por natureza, sem questionamento sobre suas origens e motivações que lhes deram sentido. Esses são alguns dos aspectos por trás do comportamento acrítico que favorece a visão determinista e instrumental do desenvolvimento tecnológico.

Por sua vez, “[...] o aperfeiçoamento do objeto técnico oblitera os vestígios do trabalho de sua construção e as forças sociais que estavam em jogo quando o seu desenho foi fixado. É este processo que ajusta o objeto ao seu nicho e, portanto, à oclusão de sua história" (FEENBERG, 2009, p. 104). A isso se denomina o "paradoxo da origem", o qual esconde uma história, uma ideologia, um interesse. Os valores conceptivos embutidos na tecnologia passam despercebidos, porém continuam válidos enraizados no código técnico.

Assim, "[...] o fato de as tecnologias poderem ser destacadas dos seus nichos apropriados significa que elas podem ser importadas sem trazer junto todos os elementos contextuais necessários para o seu correto funcionamento" (FEENBERG, 2009, p. 105). Este processo é denominado de descontextualização (Figura 2), "[...] em que os objetos estão fora de seus contextos originais e expostos à análise e à manipulação, enquanto os sujeitos forem posicionados para um controle a distância" (p. 106).

Figura 2

Processo de descontextualização da tecnologia

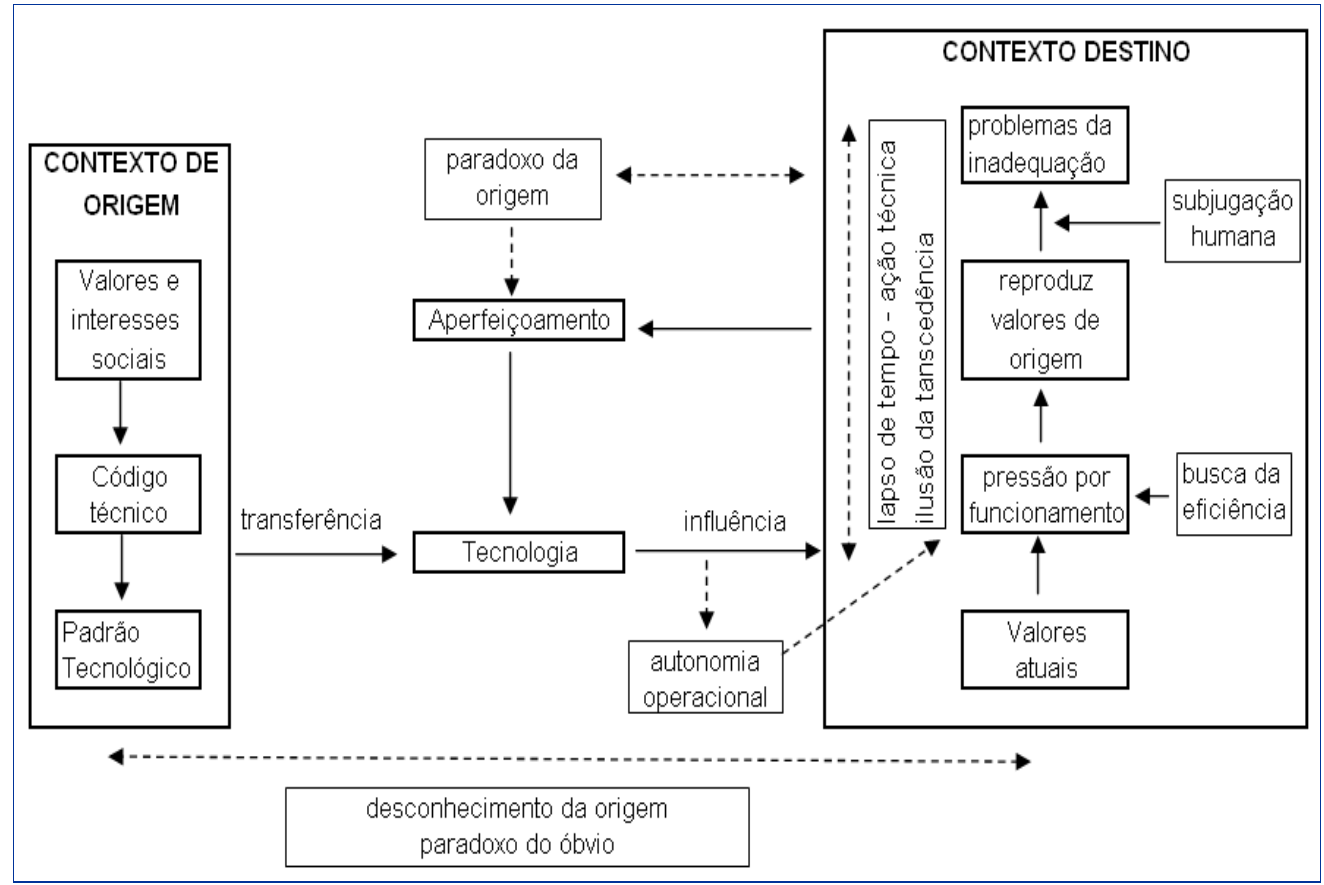

Fonte: Desenvolvido pelos autores com base em Feenberg (2004), Feenberg (2005) e Feenberg (2009).

A capacidade tecnológica da descontextualização permite que a tecnologia possa ser retirada de seu ambiente original e utilizada em um ambiente distinto. Porém, em razão de seu design, para se tornar funcional se faz necessário alterar o novo ambiente segundo as condições de sua origem, o que quer dizer incutir naquele os seus valores conceptivos. Inevitavelmente, quando da utilização de uma tecnologia estrangeira, os valores locais serão preteridos pelos valores importados na tecnologia. 
Por sua vez, o controle a distância é possível em função de o "[...] controle gerencial agir tecnicamente sobre as pessoas, estendendo a hierarquia dos sujeitos e dos objetos técnicos para as relações humanas na perseguição da eficiência", conforme enfatiza Feenberg (2005, p. 4). Disso decorre a autonomia operacional, que permite aos detentores das tecnologias "[...] reproduzir[em] as condições de sua própria supremacia a cada repetição das tecnologias que comandam. A tecnocracia é uma extensão de tal sistema à sociedade como um todo em resposta à propagação da tecnologia e da gerência em cada setor da vida social” (p. 5).

Por outro lado, "[...] a autonomia operacional do gerenciamento e da administração posiciona-os em uma relação técnica com o mundo" (FEENBERG, 2005, p. 4). Essa condição privilegiada permite aos detentores da tecnologia tomar decisões independentemente dos interesses locais, excluindo a participação de grupos sociais não dominantes no processo de desenvolvimento. Nisso reside a orientação do desenvolvimento tecnológico voltado a atender as demandas do mercado (oferta e demanda) e não a necessidade da sociedade, especialmente das comunidades locais que deveriam ser as mais beneficiadas pelo emprego da tecnologia.

Cabe destacar que "a implicação mais significativa dessa abordagem tem a ver com os limites éticos dos códigos elaborados sob a regra da autonomia operacional. Esse mesmo processo em que os capitalistas e os tecnocratas sentem-se livres para tomar decisões técnicas" (FEENBERG, 2004, p. 10), sem considerar as realidades locais. Neste caso, a tecnologia, em vez de ser um instrumento de emancipação de seus beneficiários, acaba por se tornar um meio de exclusão ao desconsiderar seus valores.

O caso claro de descontextualização baseada na autonomia operacional reside na transferência de tecnologia nos moldes tradicionais como escolha por países não desenvolvidos ou em desenvolvimento para alavancar o "desenvolvimento" de uma nação.

Somente a democratização da tecnologia pode ajudar. Isto requer em primeira instância a quebra da ilusão da transcendência pela revelação dos retornos ao ator técnico. A propagação do conhecimento por si não é o bastante para realizá-la. Para que o conhecimento seja tomado seriamente, a escala dos interesses representados pelo ator deve ser ampliada para tornar mais difícil de excluir o retorno do objeto em grupos destituídos de poder. Mas somente uma aliança democraticamente constituída de atores, envolvendo estes grupos, estará suficientemente exposta às consequências de suas próprias ações para resistir a projetos prejudiciais e designs fora de contexto (FEENBERG, 2005, p. 5).

Nesse sentido, para que haja a democratização da tecnologia é preciso privilegiar os valores que foram excluídos no processo de design e concretizá-los em novos arranjos técnicos, o que compreende "[...] reverter o processo de descontextualização, contextualizando a tecnologia, promovendo a qualificação da 'funcionalidade original' para uma orientação para um mundo novo que envolva aqueles mesmos objetos e sujeitos”, ressalta Feenberg $(2005$, p. 3).

Estratégias que "combinam os valores de diversos atores por meio de combinações inteligentes acabam por gerar [...] a multiplicação das funções servidas pela estrutura da tecnologia. Desta forma, em contextos mais amplos ou mesmo negligenciados pode-se trazer à tona um design tecnológico sem perda da eficiência" (FEENBERG, 2005, p. 7).

Em síntese, a visão oferecida pela Teoria Crítica da Tecnologia permite desvelar a estrutura por trás da tecnologia por meio da compreensão dos diversos elementos envolvidos no processo histórico-social do desenvolvimento tecnológico, fornecendo aos agentes de desenvolvimento subsídios para o exercício crítico da escolha tecnológica. 


\section{Tecnologia Social}

Inserida como um dos programas da Secretaria de Ciência e Tecnologia para a Inclusão Social (SECIS), a “[...] Tecnologia Social compreende produtos, técnicas e/ou metodologias reaplicáveis, desenvolvidas na interação com a comunidade e que representem efetivas soluções de transformação social" (MCT, 2011, p. $1)$.

A SECIS foi instituída pelo governo federal, com a missão de "[...] promover a inclusão social, por meio de ações que melhorem a qualidade de vida, estimulem a geração de emprego e renda e promovam o desenvolvimento sustentável, através da difusão do conhecimento" (SECIS, 2003, p. 1). Tendo como eixo prioritário o fomento de tecnologias voltadas ao desenvolvimento social, apoia diversos projetos voltados à transformação social; entre estes, a Tecnologia Social (TS), consolidando-a como política pública.

No entanto, a TS não é fruto de uma norma política, mas, sim, de um esforço conjunto de diversos atores (setor público, setor privado e sociedade organizada) que construíram uma proposta tecnológica, mediante discussões provenientes do projeto Centro Brasileiro de Referência em Tecnologia Social (CBRTS), experiências diversas com tecnologias alternativas e uma formulação organizada (marco analítico conceitual) de princípios e parâmetros que deram origem à TS (ITS, 2004), mais tarde complementada pela Adequação Sociotécnica (DAGNINO, BRANDÃO e NOVAES, 2004). Esses esforços foram empreendidos no intuito de que a TS, em sua concepção e aplicação, tivesse como alicerce uma adequada contextualização históricosocial e uma reflexão teórica e prática dos valores pretendidos para a sociedade.

Fruto de seu arcabouço teórico, a TS tem como características diferenciadoras: inversão da posição do beneficiário da tecnologia de consumidor para ator central, o que rompe com a relação de dependência tecnológica; desenvolvimento mediante interação com a comunidade, respeitando a cultura local e promovendo seus valores; democratização do conhecimento, que é disponibilizado publicamente; orientação pela necessidade de seus beneficiários em vez da orientação ao mercado; projeção com o propósito de promover a transformação social, observadas as dimensões do desenvolvimento sustentável.

Essas e outras características, delineadas na análise, denotam o potencial da TS como proposta de resgate à adequada relação entre ciência, tecnologia e sociedade.

\section{Resultados e Análises}

Considerando a necessidade de repensar o papel da ciência e tecnologia - frente às demandas da sociedade na promoção de um desenvolvimento tecnológico sustentável, nesta seção são apresentados análises e resultados do estudo realizado, que adota como hipótese a contribuição efetiva da Tecnologia Social para a adequada relação entre a ciência, a tecnologia e a sociedade.

Por meio da descrição da TS, são tecidas diversas considerações e proposições, apoiadas por uma visão crítica acerca desse fenômeno tecnológico e sua aderência à proposta da CTS.

Como já destacado, a TS é fruto de um esforço coletivo direcionado ao desenvolvimento de uma formulação organizada, ou também denominada marco analítico conceitual, composta por um conceito central e três eixos: princípios, parâmetros e adequação sociotécnica.

A começar por sua definição conceitual, a TS é entendida como um "[...] conjunto de técnicas e metodologias transformadoras, desenvolvidas e/ou aplicadas na interação com a população e apropriadas por ela, que representam soluções para inclusão social e melhoria das condições de vida" (ITS, 2004, p. 26).

Pensada como um projeto dialético, a TS tem em posição de destaque a figura do desenvolvedor e do beneficiário, de modo que estes, no decorrer do processo de desenvolvimento tecnológico, não sejam mais 
distintos ou separados em função de sua concepção e/ou desenvolvimento interativo. Esse posicionamento destaca a importância da sociedade como fonte de conhecimento e a retira da condição passiva de um processo unilateral. Destarte, está implícito, na TS, o papel participativo do usuário na criação da solução tecnológica, cujas considerações do contexto social têm maior probabilidade de solucionar seu problema, dada a contextualização destacada por Feenberg (2009).

Cabe destacar que no processo de desenvolvimento da tecnologia: tem-se as escolhas fundamentais de valores conceptivos e que mais tarde serão reforçadas pela tecnologia quando da sua aplicação; tem-se a modelagem por meio do código técnico ou escolha técnica (FEENBERG, 2005), e que irá dar sustentação a um estilo de vida; dá-se a contextualização da tecnologia em sintonia com o seu ambiente, reforçando a cultura local ou ainda a recontextualização na adaptação da tecnologia ao ambiente de aplicação. Tais aspectos justificam a necessidade do controle social do desenvolvimento tecnológico, necessariamente pensado mediante uma relação dialética com a sociedade.

O primeiro eixo corresponde aos princípios compostos por quatro preceitos que servem de base e permeiam as ideias relacionadas à TS (Quadro 2).

\section{Quadro 2}

\section{Princípios da Tecnologia Social}

- Aprendizagem e participação são processos que caminham juntos: aprender implica participação e envolvimento; e participar implica aprender.

- A transformação social implica compreender a realidade de maneira sistêmica: diversos elementos se combinam por meio de múltiplas relações para construir a realidade.

- A transformação social ocorre na medida em que há respeito às identidades locais: não é possível haver transformação se não mediante as especificidades da realidade existente.

- Todo indivíduo é capaz de gerar conhecimento e aprender: a partir do momento que está inserido numa cultura e em contato com o mundo, todo indivíduo produz conhecimento e aprende por meio dessa interação.

Fonte: ITS (2004, p. 26).

Nos quatro princípios, estão implícitos a crença na capacidade do indivíduo e o respeito à sua cultura. Capacidade de aprender, participar e de gerar conhecimento são enfatizados e posicionados como pressupostos básicos de toda ação que deve ensejar a emancipação do indivíduo frente à sua realidade, por sua vez, compreendida e respeitada. Somente por meio da compreensão da cultura local e da participação efetiva do indivíduo é possível gerar transformação social. De outro modo, apenas por meio de uma intervenção participativa holística é possível compreender a complexidade do problema social e oferecer um caminho que permita resgatar o indivíduo de sua situação de fragilidade, valorizando sua capacidade de criar soluções próprias, mesmo que assistidas.

O desenvolvimento proposto da TS leva em consideração a necessidade de quebrar a relação de dependência tecnológica do indivíduo ao artefato ou processo, o que "[...] implica na construção de respostas de modo coletivo pelos que irão se beneficiar dessas soluções e que atuam com autonomia implicando [...] novas interpretações sobre formas de conceber estratégias e políticas ligadas ao conhecimento científico ou tecnológico" (VENTURA, SANTOS e FREITAS, 2010, p. 6). Rodrigues e Barbieri (2008) ressaltam que o ato de participar ativamente do processo de construção da solução tecnológica coloca o indivíduo em uma posição de produtor da tecnologia - influenciando diretamente as escolhas tecnológicas - e não mero consumidor de produtos desenvolvidos por especialistas.

Tal conotação alinha-se com os pressupostos da visão da teoria crítica, segundo a qual o desenvolvimento tecnológico é controlado pelo homem, que tem a capacidade de influenciá-lo mediante participação na sua 
produção pela apropriação de seus valores. Esse processo caracteriza o controle social da tecnologia, mediante o qual o indivíduo deixa o papel de mero espectador do desenvolvimento tecnológico e passa a ter o exercício de poder de decisão, que lhe permite alcançar sua emancipação.

O segundo eixo é o dos parâmetros da TS definidos como critérios de análise das ações sociais, e constituem elementos essenciais na caracterização de uma TS (Quadro 3).

\section{Quadro 3}

\section{Parâmetros da Tecnologia Social}

Razão de ser: visa à solução de demandas sociais concretas, vividas e identificadas pela população. Processos de tomada de decisão: formas democráticas de tomada de decisão, mediante estratégias especialmente dirigidas à mobilização e à participação da população.

Papel da população: participação, apropriação e aprendizagem por parte da população e de outros atores envolvidos.

Sistemática: planejamento e aplicação de conhecimento de forma organizada.

Construção de conhecimentos: produção de novos conhecimentos por meio da prática.

Sustentabilidade: visa à sustentabilidade econômica, social e ambiental.

Ampliação de escala: gera aprendizagens que servem de referência para novas experiências; gera, permanentemente, as condições favoráveis que tornaram possível a elaboração das soluções, de forma a aperfeiçoá-las e multiplicá-las

Fonte: ITS (2004, p. 28-30, grifo nosso).

Os parâmetros podem ser consolidados segundo três focos ou preocupações distintas e dependentes: propósito, pessoas e processo. No propósito estão os parâmetros quanto à sua razão de ser e quanto à sustentabilidade, e dizem respeito à finalidade da TS de solucionar demandas sociais percebidas pela comunidade mediante ações que visem a um desenvolvimento sustentável ambiental, econômica e socialmente, ou seja, que contemplem a dimensão material da sustentabilidade, pelo atendimento de seus imperativos (ROBINSON e TINKER, 1997) e que remetem ao desenvolvimento tecnológico voltado à sociedade.

A alternativa da TS coaduna-se com as reivindicações da sociedade por um maior envolvimento e controle da Ciência e Tecnologia no intuito de garantir que os investimentos, em especial públicos, sejam direcionados prioritariamente pelas necessidades da própria sociedade que os mantém. Deve-se, assim, gerar um desenvolvimento efetivamente sustentável e que, mediante o atendimento de seus imperativos, possa contemplar todas as suas dimensões: ambiental, econômica, geográfica, política e social (SACHS, 2008).

O segundo foco são as pessoas e compreende os parâmetros em relação aos processos de tomada de decisão e à construção de conhecimentos. Como extensivamente descrito até o momento, o elemento humano é "peça chave" da metodologia da TS, que deve ser concebida mediante processo efetivo de construção social. Nisso reside o maior desafio da relação CTS, o de romper uma cultura na qual o indivíduo em sua interação com a tecnologia, desde o processo de industrialização, cada vez mais tem sido colocado em posição passiva, alienante e dependente, uma vez que ela se lhe apresenta pronta e acabada.

Para que haja o resgate da técnica, o indivíduo deve participar efetivamente do processo por meio da mobilização, da tomada de decisão e, também, da concretização da tecnologia mediante a prática do fazer, ou seja, deve haver apropriação da tecnologia, tanto em termos de conhecimento como de sua posse. Nisso reside o rompimento do posicionamento da neutralidade e autonomia da tecnologia para a condição de controle e condicionamento de valores, assumida pela visão crítica da tecnologia (DAGNINO, BRANDÃO e NOVAES, 2004; FEENBERG, 2004). 
O terceiro, e último foco, diz respeito ao processo e compreende os parâmetros em relação à sistemática e à ampliação de escala. No foco do processo está a preocupação com a metodologia ou o modo de promover a intervenção pela TS. A considerar que a construção social é um processo complexo, faz-se necessário um adequado planejamento das ações com consequente aplicação organizada, de modo que esse conhecimento não se perca, mas seja armazenado e compartilhado. Assim, torna-se possível a democratização do saber e a ampliação do acesso ao conhecimento (ITS, 2004).

Cabe destacar que "[...] uma tecnologia social não gera mais riqueza por ser inédita e restringir a abrangência de seu uso a poucos. Ao contrário, ela cumpre seu objetivo se consegue, a partir dos seus elementos constitutivos, reproduzir-se e difundir-se" (LIMA, DAGNINO e FONSECA, 2008, p. 126). Por esse processo é possível limitar ou reduzir a influência da tecnocracia no processo em decorrência do caráter coletivo do conhecimento. Tal aspecto enfatiza a apropriação social do conhecimento defendida pela CTS, de modo antagônico à orientação da $\mathrm{C} \& \mathrm{~T}$, uma vez que, desenvolvida pela iniciativa privada, é direcionada pela demanda de mercado e se utiliza de meios como registros e patentes para assegurar a privacidade do conhecimento. Na proposta da TS, o conhecimento é democratizado e solidarizado.

O terceiro eixo corresponde à adequação sociotécnica (AST), tributária das ideias do construtivismo, da Teoria Crítica da Tecnologia, da Teoria da Inovação e da tese forte da não neutralidade do desenvolvimento tecnológico (DAGNINO, BRANDÃO e NOVAES, 2004), e constitui uma abordagem para a operacionalização da TS, mediante a consideração de três fundamentos ou pilares: dimensão processual, visão ideológica e operacionalidade. A dimensão processual reforça a reflexão de que a "[...] tecnologia é em si mesma um processo de construção social e, portanto, político [...] que terá que ser operacionalizado nas condições dadas pelo ambiente específico onde irá ocorrer" (DAGNINO, 2007, p. 187).

Diferentemente de um produto idealizado e acabado, a TS é um processo de construção participativo, cujo resultado final dependerá do contexto e das negociações entre os atores envolvidos. Rompe com a perspectiva estática da relação usuário versus tecnologia, evidenciando a participação do usuário no processo. Na dimensão processual, tributária do construtivismo, enfatiza-se que "[...] o processo de escolha do projeto deve ser deliberado através da [...] racionalidade democrática, onde os atores subjugados interferem no processo de projeto tecnológico para moldar a tecnologia de acordo com seus próprios fins" (DAGNINO, 2007, p. 191). Assim, a justificação tecnológica é realizada por meio da racionalidade democrática e não da racionalidade técnica.

Em consonância com os princípios e parâmetros, a AST, em sua dimensão processual, enfatiza a ideia de construção social da tecnologia, que implica a participação do indivíduo e a consideração do seu contexto, reforçando a relação dialética entre a sociedade e a C\&T.

O segundo pilar, visão ideológica, liga-se à racionalidade democrática, e reflete a crença de que o conhecimento científico e tecnológico deve ser direcionado ou promovido ao desenvolvimento sustentável, ou seja, por critérios de natureza social, econômica e ambiental. Assim, deve ser concebido e desenvolvido como uma solução, ou resposta, ampliada que permita de modo holístico trazer em si elementos que atentem para considerações além do caráter técnico-econômico, mas "[...] ao conjunto de aspectos de natureza socioeconômica e ambiental que constituem a relação Ciência, Tecnologia e Sociedade" (DAGNINO, 2007, p. 187-188).

A visão ideológica reforça os aspectos definidos nos parâmetros da TS quanto à sua razão de ser e quanto à sustentabilidade, pois se referem ao fazer ciência e tecnologia enquanto política e trazem em si a força da teoria crítica da tecnologia. Nessa nova orientação, está implícita a crença da não neutralidade do desenvolvimento tecnológico, que consiste em um processo de escolha política conduzida não apenas com base em requisitos técnicos e econômicos, mas também pelos aspectos sociais e ambientais e com a efetiva participação das pessoas em seu desenvolvimento. Tal processo constitui uma inovação social, "[...] em que atores sociais interagem desde um primeiro momento para engendrar, em função de múltiplos critérios [...], um conhecimento que eles mesmos vão utilizar, no próprio lugar" (DAGNINO, 2007, p. 189). 
A respeito disso, na TS, a inovação é entendida de maneira distinta daquela originalmente concebida pelo mercado, dando lugar ao conceito de inovação social, na qual toda inovação parte prioritariamente da realidade social e não da oportunidade de mercado. Diferentemente do espaço econômico tradicional da inovação que cria riquezas para poucos, no espaço da TS o resultado positivo da inovação é coletivo, reproduzido e difundido (DAGNINO, FONSECA, NOVAES et al., 2006), daí a importância para a sistematização e ampliação de escala.

Por fim, o terceiro pilar, operacionalidade, está ligado à percepção de que a TS, diferentemente de um resultado, é um processo, por meio do qual é possível abarcar uma multiplicidade de soluções que foram definidas como modalidades por Dagnino, Brandão e Novaes (2004) (Quadro 4).

\section{Quadro 4}

\section{Modalidades de Adequação Sociotécnica da Tecnologia Social}

Uso: O simples uso da tecnologia (máquinas, equipamentos, formas de organização do processo de trabalho, etc.) antes empregada (no caso de cooperativas que sucederam a empresas falidas), ou a adoção de tecnologia convencional, com a condição de que se altere a forma como se reparte o excedente gerado, é percebida como suficiente.

Apropriação: concebida como um processo que tem como condição a propriedade coletiva dos meios de produção (máquinas, equipamentos), implica uma ampliação do conhecimento por parte do trabalhador, dos aspectos produtivos (fases de produção, cadeia produtiva etc.), gerenciais e de concepção dos produtos e processos, sem que exista qualquer modificação no uso concreto que deles se faz.

Revitalização ou Repotenciamento das máquinas e equipamentos: significa não só o aumento da vida útil das máquinas e equipamentos, mas também ajustes, recondicionamento e a revitalização do maquinário. Supõe ainda a fertilização das tecnologias 'antigas' com componentes novos.

Ajuste do processo de trabalho: implica a adaptação da organização do processo de trabalho à forma de propriedade coletiva dos meios de produção (preexistentes ou convencionais), o questionamento da divisão técnica do trabalho e a adoção progressiva do controle operário (autogestão).

Alternativas tecnológicas: implica a percepção de que as modalidades anteriores, inclusive a do ajuste do processo de trabalho, não são suficientes para dar conta das demandas por AST dos empreendimentos autogestionários, sendo necessário o emprego de tecnologias alternativas à convencional. As atividades decorrente desta modalidade são a busca e seleção de tecnologias existentes.

Incorporação de conhecimento científico-tecnológico existente: resulta do esgotamento do processo sistemático de busca de tecnologias alternativas e da percepção de que é necessária a incorporação à produção de conhecimento científico-tecnológico existente (intangível, não embutido nos meios de produção), ou o desenvolvimento, com base nele, de novos processos produtivos ou meios de produção, para satisfazer as demandas por AST. Atividades associadas a esta modalidade são processos de inovação de tipo incremental, isolados ou em conjunto com centros de P\&D ou universidades.

Incorporação de conhecimento científico-tecnológico novo: resulta do esgotamento do processo de inovação incremental em virtude da inexistência de conhecimento suscetível de ser incorporado a processos ou meios de produção para atender às demandas por AST. Atividades associadas a esta modalidade são processos de inovação de tipo radical que tendem a demandar o concurso de centros de P\&D ou universidades e que implicam a exploração da fronteira do conhecimento.

Fonte: Dagnino, Brandão e Novaes (2004, p. 37-40). 
As modalidades refletem a preocupação com a inserção do fator trabalho nas propostas de TS e consistem em uma significativa complementação, moldada por um viés pragmático, aos dois eixos (princípios e parâmetros) definidos pelo CBRTS, que, a despeito de apresentar um amplo escopo teórico norteador da TS, não manifestou claramente a proposta de uma tecnologia voltada aos meios de produção especificamente.

A preocupação com o fator trabalho é justificada pela percepção de que a causa da exclusão dos indivíduos está na órbita do trabalho, como destacam Lima, Dagnino e Fonseca (2008, p. 122): “[...] é importante ressaltar que o conceito de Tecnologia Social não deveria ser estendido a qualquer atividade ou projeto (ou, genericamente, metodologia) concebido com vistas à redução da exclusão social, mas sim, como processos e projetos que têm como referência a produção de bens e serviços", caso contrário as soluções acabariam por contribuir não com o desenvolvimento sustentável, mas, sim, com um desenvolvimento socialmente benigno, promovendo ações assistencialistas, ou ainda com um desenvolvimento ambientalmente benigno com o risco de estagnação do crescimento.

É importante, para o processo de emancipação do indivíduo, que a solução tecnológica permita ao seu usuário um meio de obter sua própria renda, com oportunidade de condições de autoinserção na dinâmica de seu contexto social. Soluções assistencialistas apenas amenizam o sofrimento da exclusão social em vez de solucionar o problema efetivamente. Desse modo, quando possível, entre uma e outra solução, a que possibilitar rendimentos ao seu usuário, sem desconsiderar as demais dimensões do desenvolvimento sustentável, deve ser preferida.

Cada modalidade foi pensada da perspectiva da produção de bens e serviços mediante o controle social da tecnologia e compreendem dois focos distintos: a forma de organização e a manutenção/melhoria do processo.

No primeiro foco, forma de organização, estão as modalidades: uso, apropriação e ajuste do processo de trabalho. Compreendem a orientação de que a tecnologia deve ser empregada em um contexto que privilegia a propriedade coletiva, assim como a forma de trabalho envolvida entre seus usuários, abdicando do modelo capitalista de relação patrão e empregado. Ainda, é importante destacar que a forma coletiva de trabalho proporciona a gestão compartilhada ou autogestão do aparato tecnológico, ampliando o conhecimento por parte do trabalhador e eliminando a autonomia operacional, e, por conseguinte, a ação da tecnocracia. Desse modo, reforça o compromisso de um desenvolvimento tecnológico (C\&T) para a sociedade, sendo um meio e não um fim gerador de dependência, dada a ausência do controle social sobre a tecnologia.

No segundo foco, manutenção/melhoria do processo, estão as demais modalidades. Consistem na orientação para um processo de inovação social que permita gerar condições de manutenção da solução tecnológica, com a valorização e incorporação de conhecimentos e tecnologias alternativas já existentes, assim como a melhoria com base na aplicação de uma engenharia social, com o envolvimento de diversos atores responsáveis pela geração da ciência e de novas tecnologias. Entre estes, merecem destaque especial os centros de pesquisa e as universidades públicas, por possuírem, entre suas funções, um forte compromisso com a sociedade, e, também porque ocupam uma posição relativamente autônoma, como destaca Dagnino (2002, p. 24):

Mas a ciência possui características específicas que não são diretamente assimiláveis aos valores capitalistas. Algo que lhe garante uma autonomia relativa e até independência em relação ao Estado e aos detentores dos meios de produção. Sendo assim, o papel hegemônico que possui a comunidade de pesquisa no processo decisório da política de $\mathrm{C} \& \mathrm{~T}$ a torna $\mathrm{o}$ ator em melhores condições para iniciar um necessário processo de sua reorientação no sentido de alterar a trajetória da C\&T e antecipar demandas da sociedade que não encontram possibilidade de serem satisfeitas dada a atual correlação de forças políticas. 
O eixo da AST, de modo geral, corresponde a um grande esforço, por parte dos estudiosos da TS, de complementar os princípios e parâmetros definidos pelo projeto CBRTS (ITS, 2004), na busca da coesão entre o plano conceitual, que expressa uma concepção de intervenção social, e o plano material. Pode, assim, proporcionar maior efetividade da TS no intuito de reverter a exclusão social provocada pelo desenvolvimento tecnológico (LIMA, DAGNINO e FONSECA, 2008). Em resumo, na TS, em cada um dos seus eixos, está explicita a necessidade de inverter a posição entre a tecnologia e seu beneficiário, colocando este e seu contexto em primeiro lugar. A proposta é conceber suportes adequados aos estilos de vida desejados, promover uma relação adequada entre a ciência, a tecnologia e a sociedade.

\section{Considerações finais}

A Tecnologia Social foi concebida como proposta crítica ao paradigma dominante do desenvolvimento tecnológico baseado no modelo linear da Ciência e Tecnologia (STOKES, 2005), mediante arcabouço analítico, teórico e prático alinhado com o compromisso ético de resgate dos valores de igualdade, equidade e solidariedade diante das questões econômicas, como defendido por Sachs (2008).

Tal proposta foi construída com base em três eixos (princípios, parâmetros e adequação sociotécnica). Eles moldam a proposta tecnológica e trazem em si uma série de elementos essenciais que visam resgatar a adequada relação entre a ciência, a tecnologia e a sociedade, ou seja, na qual todo desenvolvimento tecnológico está em função, prioritariamente, das necessidades humanas e direcionado a contribuir com um desenvolvimento sustentável.

A adoção da TS resulta na ampliação do conhecimento, a que Rodrigues e Barbieri (2008) denominaram de ideia de múltiplas direções na produção do conhecimento, derivado de múltiplas fontes (diferentes atores sociais, interesses e valores) que colaboram entre si na busca da solução tecnológica, suplantando o modelo linear e efetivando o processo de construção social da tecnologia. Tal colaboração, quando constituída de uma aliança democrática, possibilita condições suficientes para resistir aos modelos tecnológicos estranhos ao seu contexto, como enfatizado por Feenberg (2005).

Ainda, a preponderância do ambiente social e suas demandas como fonte de fomento à investigação científica e consequente desenvolvimento tecnológico denotam a adequação da relação ciência, tecnologia e sociedade, evitando, assim, que a escolha tecnológica seja influenciada por valores estranhos ao contexto de sua aplicação.

Ao considerar o objetivo proposto da pesquisa, é possível concluir que os resultados obtidos confirmam a aderência da Tecnologia Social à proposta da adequada relação ciência, tecnologia e a sociedade. Assim, a TS destaca-se como uma proposta arrojada e complexa, que, diante dos modelos tradicionais de desenvolvimento tecnológico, constitui-se em um avanço significativo na medida em que possibilita: emancipar o indivíduo na condição de usuário da tecnologia; efetivar um processo de construção social mais democrático; valorizar a aprendizagem; promover o respeito à cultura local; colocar as demandas sociais como origem e propósito da tecnologia; permitir a apropriação da tecnologia pelos seus usuários; contribuir com a sustentabilidade; promover a democratização do conhecimento; gerar transformação social e multiplicidade de soluções. 


\section{Referências}

BAZZO, W. A.; LINSINGEN, I.V.; PEREIRA, L. T. V. O que são e para que servem os estudos CTS. Universidade Federal de Santa Catarina, Florianópolis, 2000.

BOCAYUVA, P. C. C. Tecnologia Social na transição paradigmática. In: OTERLOO, A. et al. Tecnologias Sociais: caminhos para a sustentabilidade. Brasília: s.n., 2009. 117-129 p.

CUPANI, A. O. A tecnologia como problema filosófico: três enfoques. Scientiae Studia, v. 2, n. 4, p. 493-518, 2004.

DAGNINO, R. P. Enfoques sobre a relação ciência, tecnologia e sociedade: neutralidade e determinismo. 2002. 1-27 p. Disponível em: <http://www.oei.es/salactsi/rdagnino3.htm>. Acesso em: 05 mar. 2011.

A Tecnologia Social e seus desafios. In: FBB. Tecnologia Social: uma estratégia para o desenvolvimento. Rio de Janeiro: FBB, 2004. 187-210 p.

2007.

Um debate sobre a tecnociência: neutralidade da ciência e determinismo tecnológico. Campinas: Unicamp,

.; BRANDÃO, F. C.; NOVAES, H. T. Sobre o marco analítico-conceitual da Tecnologia Social. In: FBB. Tecnologia Social: uma estratégia para o desenvolvimento. Rio de Janeiro: FBB, 2004. 15-64 p.

et al. Política científica e tecnológica e tecnologia social: buscando convergência. In: I FÓRUM NACIONAL DA REDE DE TECNOLOGIA SOCIAL, 1., 2006, Salvador. Anais eletrônicos... Disponível em:<http://www.rts.org.br/publicacoes/anais-1b0-forum-nacional-da-rts>. Acesso em: 10 ago. 2011.

FEENBERG, A. Critical Theory of Technology. New York and Oxford, Oxford University Press, 1991.

Teoria Crítica da tecnologia. Texto original "Critical theory of technology". Tradução da Equipe de Tradutores do Colóquio Internacional "Teoria Crítica e Educação”. Piracicaba: Unimep, 2004.

Cinco paradoxos da tecnologia e da política de desenvolvimento. In: OTERLOO, A. et al. Tecnologias Sociais: caminhos para a sustentabilidade. Brasília: s.n., 2009. 99-116 p.

Teoria Crítica da tecnologia: um panorama. 2005. Texto originalmente publicado em Tailor-Made

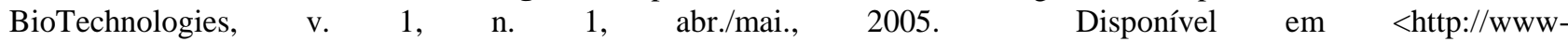
rohan.sdsu.edu/faculty/feenberg/feenberg_luci.htm>. Acesso em: 13 jan. 2011.

HAMMARSKJÖLD. What now: the 1975 Dag Hammarskjöld Report. New York: United Nations General Assembly, 1975.

ITS - Instituto de Tecnologia Social. Tecnologia Social no Brasil: direito à ciência e ciência para cidadania. Caderno de Debate. São Paulo: Instituto de Tecnologia Social: 2004.

LIMA, M. M. T.; DAGNINO, R. P.; FONSECA, R. Um enfoque tecnológico para inclusão social. Revista Perspectivas em Políticas Públicas, v. 1, n. 2, p. 117-119, jul./dez. 2008.

MARCONI, M. A.; LAKATOS, E. M. Fundamentos de metodologia científica. 5. ed. São Paulo: Atlas, 2003.

MCT - Ministério da Ciência e Tecnologia. Tecnologias sociais: descrição da Tecnologia Social. 2011. Disponível em <http://www.mct.gov.br/index.php/content/view/308089.html>. Acesso em: 19 fev. 2011.

NOVAES, H. T.; DAGNINO, R. O fetiche da tecnologia. Revista Organizações \& Democracia, v. 5, n. 2, p. 189-210, dez. 2004 
PNUD, Programa das Nações Unidas para o Desenvolvimento. Destaques Relatório de Desenvolvimento Humano 2001. Disponível em <http://www.pnud.org.br/hdr/hdr2001/P-1.pdf>. Acesso em: 12 fev. 2011.

RICHARDSON, R. J. Pesquisa Social: métodos e técnicas. São Paulo: Atlas, 1999.

ROBINSON, J. Squaring the circle? Some thoughts on the idea of sustainable development. Ecological Economics, v. 48, n. 4, p. 369-384, 2004.

.; TINKER, J. Reconciling ecological, economic, and social imperatives: a new conceptual framework. In: SCHRECKER, T. (Ed.), Surviving Globalism: social and environmental dimensions. London, New York: Macmillan, St. Martin's Press, 1997.

RODRIGUES, F. H. Investimento direto estrangeiro e empresas transnacionais no Brasil: reflexões de pensadores da CEPAL (perspectiva histórica do pós-guerra ao início do século XXI). 2006. 123 p. Dissertação (Mestrado de Ciências Econômicas) - Instituto de Economia. São Paulo: Universidade Estadual de Campinas, 2006.

RODRIGUES, I.; BARBIERI, J. C. A emergência da Tecnologia Social: revisitando o movimento da tecnologia apropriada como estratégia de desenvolvimento sustentável. Rev. Adm. Pública, v. 42, n. 6, p. 1069-94, nov./dez. 2008.

SACHS, I. Desenvolvimento numa economia mundial liberalizada e globalizante: um desafio possível? Estudos Avançados, São Paulo, v. 11, n. 30, p. 213-242. 1997.

Desenvolvimento: includente, sustentável, sustentado. Rio de Janeiro: Garamond, 2008.

SECIS. Apresentação SECIS. Secretaria de Ciência e Tecnologia para Inclusão Social. 2003. Disponível em <www.mi.gov.br/download/download.asp?endereco=/pdf/.... >. Acesso em: 24 abr. 2012.

STOKES, D. E. O quadrante de Pasteur: a ciência básica e a inovação tecnológica. Campinas, SP: Editora da UNICAMP, 2005.

TRIGUEIRO, M. G. S. Sociologia da Tecnologia: bioprospecção e legitimação. São Paulo: Centauro, 2009.

TRIVIÑOS, A. N. S. Introdução à pesquisa em Ciências Sociais: a pesquisa qualitativa em educação. São Paulo: Atlas, 2010

VENTURA, A. C.; SANTOS, M. A.; FREITAS, E. J. Inovação em busca do desenvolvimento sustentável: a tecnologia social como instrumento de alavancagem. In: encontro nacional de pesquisadores em gestão social (ENEGEP), 4., 2010, Lavras. Anais eletrônicos... $\quad$ Disponível em $<$ http://anaisenapegs2010.cariri.ufc.br/index.php?searchword=tecnologia+social\&ordering=\&searchphrase=all\&Itemid =1\&option=com_search $>$. Acesso em: 10 jun. 2011. 1-17 p.

WCED. Common Future. Report by the World Commission on Environment and Development. Kenya, 1987. Disponível em < http://upload.wikimedia.org/wikisource/en/d/d7/Our-common-future.pdf>. Acesso: 05 jan. 2011. 